\section{Childish concerns}

\author{
P. E. Bryant
}

A Good Enough Parent: The Guide To Bringing Up Your Child. By Bruno Bettelheim. Thames \& Hudson/Knopf: 1987. Pp.377. £12.95, \$18.95.

THE relationship between science and practical necessity is often an uneasy one. People had to get on with the job of building houses and bridges, treating the sick, managing the economy and bringing up children long before there was a scientific rationale for what they were doing. In some areas our scientific knowledge has supplanted the practical expertise which preceded it by so many centuries; we now know, for example, what makes bridges stand up and why some medicines work.

Other subjects have not reached this fortunate and exact state. It is not at all clear yet what makes an economy prosper, nor why some children have a calm and happy childhood and others do not. Yet the practical problems still have to be tackled. The result is that in many subjects, of which of course child psychology is one, there are at least two levels of discourse about the same questions. On the one hand we have the wise men and women, often with many years of experience in clinics or classrooms, who have to make immediate decisions about how to solve a wide range of children's problems. On the other there are the scientists struggling, often to no avail, with the extremely complicated matter of cause and effect in children's emotional and intellectual growth.

What should we be hearing from these two sets of people? At first sight the answer seems quite straightforward. The practitioners should be telling us: "Look, it seems to me that when I do A with young children the result is usually $B$; so if you also want to achieve B try method A". The scientist's more hesitant dictum should take the form: "I had hypothesis X about the underlying mechanisms which control young children's development and this led to the prediction $\mathrm{Y}$ which I tested in this or that manner with some success". No one, I think, would dispute the value of either of these very different lines of debate, but the trouble is that the two sometimes become confusingly crossed. Bruno Bettelheim's new book is a case in point.

Bettelheim is a distinguished practitioner and a scientist too. For many years he has run a clinic for disturbed children. His ideas about childhood autism are well known and he has written interestingly and entertainingly about his work on children's reading and about his observations of the life of young children in Israeli kibbutzim. His latest book is about how parents should behave towards their children.

The book's main themes are easy to describe. Bettelheim thinks that parents should reflect on the reasons for their own reactions towards their children, particularly when parent and child are in dispute. He argues that the real reason for these disputes often lies in the parent's own childhood difficulties and frustrations, and that once this is understood the parent will become more flexible and the difficulty should go away. Bettelheim also claims that children do not often do wrong knowingly and deliberately, and that parents ought to acknowledge this when they remonstrate with their child. Bettelheim abhors punishment and even warns parents against overwhelming a child with logic. Browbeating a child into admitting that he is in the wrong does no good and probably puts a child off rational argument into the bargain. In the final part of the book Bettelheim dwells on the importance of play and fantasy in childhood.

The book has many advantages. It is written in a relaxed and attractive way. Though many of the themes, such as the importance of play, are familiar ones, the anecdotes with which Bettelheim illustrates them are usually quite striking. It is also useful to be reminded of psychoanalytical accounts of relationships between children and their parents, because these have received little attention lately.

The trouble with the book is that it is full of confident assertions for which we have no real evidence. We can take as an example Bettelheim's claim that parents often unknowingly re-enact disputes which they themselves had as children with their own parents. The claim is plausible, and others have made much the same suggestion; Philip Larkin, for example, with his lines about parents: "They hand on all the faults they had, and add some extra just for you". Yet I know of no hard evidence for the suggestion that this happens, and worse still I could find no attempt in the book to argue against another possible explanation for why this pattern might occur. One alternative to the psychoanalytical explanation is genetic. Children may relive their parents' difficulties because they share their parents' genetic make-up.

Bettelheim's justification for his consistent failure to back his ambitious claims with anything but the flimsiest evidence might be that these are issues which are too complex for clear empirical research. But this excuse would not work with some of the issues in the book on which there has in fact been a great deal of research.

The most obvious example is the question of the effects of play. This has attracted the attention of a large number of research workers. It cannot be said that

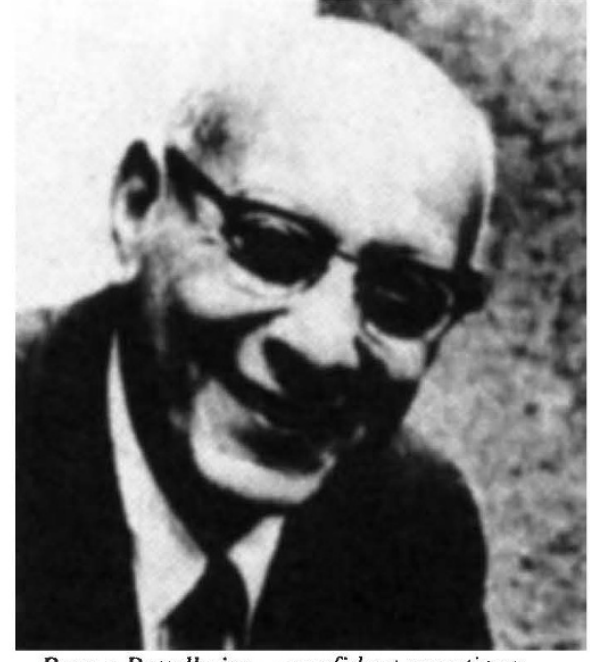

Bruno Bettelheim - confident assertions.

their efforts have provided us with the final answer, but the evidence is certainly worth discussing and it ought to be mentioned by anyone making theoretical statements on the subject. Bettelheim's omission is a clear sign that he does not consider that a sound empirical base is needed for his theoretical ideas. That is a pity, because many of those ideas are interesting.

P. E. Bryant is Watts Professor in the Department of Experimental Psychology, University of Oxford, South Parks Road, Oxford OX1 3UD, $U K$

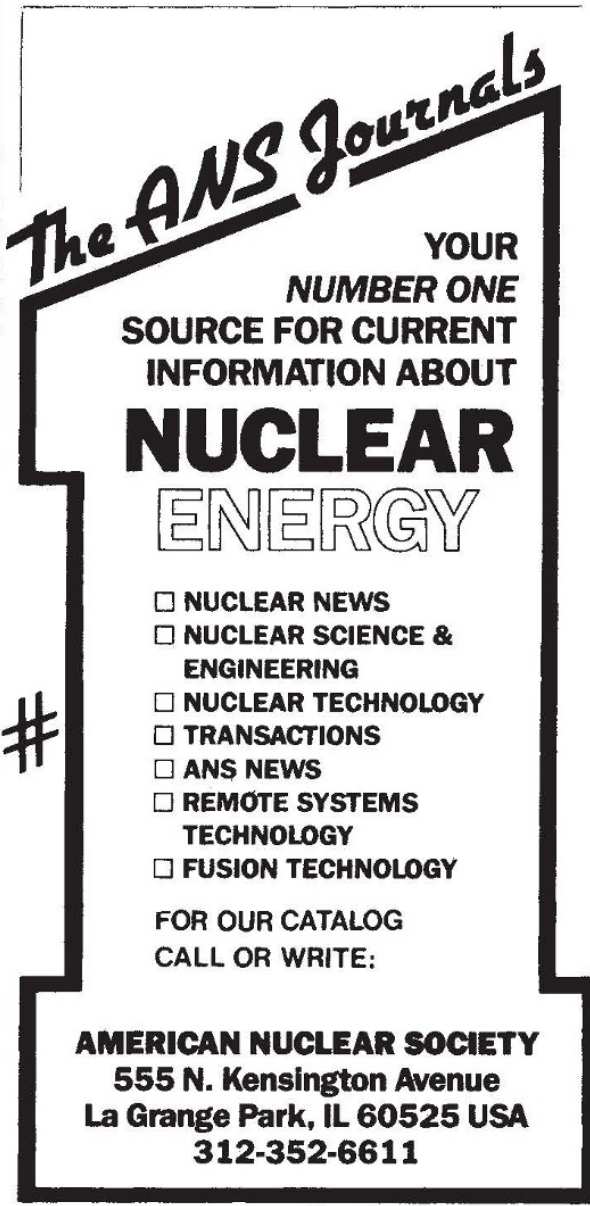

Reader Service No.16 